\title{
Molecular analysis of T-B-NK+ severe combined immunodeficiency and Omenn syndrome cases in Saudi Arabia
}

\author{
Osama Alsmadi ${ }^{1}$, Abdulaziz Al-Ghonaium², Saleh Al-Muhsen²,3, \\ Rand Arnaout ${ }^{2}$, Hasan Al-Dhekri' ${ }^{2}$, Bandar Al-Saud ${ }^{2}$, Fadi Al-Kayal ${ }^{1}$, \\ Haya Al-Saud ${ }^{1}$ and Hamoud Al-Mousa*2
}

Address: ${ }^{1}$ Genetics Department, Research Center, King Faisal Specialist Hospital \& Research Center, Riyadh, Saudi Arabia, ${ }^{2}$ Department of Pediatrics, King Faisal Specialist Hospital \& Research Center, Riyadh, Saudi Arabia and ${ }^{3}$ Department of Pediatrics, College of Medicine, King Saud University, Riyadh, Saudi Arabia

Email: Osama Alsmadi - oalsmadi@gmail.com; Abdulaziz Al-Ghonaium - f23039@kfshrc.edu.sa; Saleh Al-Muhsen - smohsen@kfshrc.edu.sa; Rand Arnaout - f69195@kfshrc.edu.sa; Hasan Al-Dhekri - f41483@kfshrc.edu.sa; Bandar Al-Saud - f48048@kfshrc.edu.sa; Fadi Al-

Kayal -f77374@kfshrc.edu.sa; Haya Al-Saud -f89760@kfshrc.edu.sa; Hamoud Al-Mousa* - hamoudalmousa@kfshrc.edu.sa

* Corresponding author

Published: 13 November 2009

BMC Medical Genetics 2009, 10:116 doi:10.1/86/1471-2350-10-116
Received: 29 April 2009

Accepted: 13 November 2009

This article is available from: http://www.biomedcentral.com/I47I-2350/I0/II6

(C) 2009 Alsmadi et al; licensee BioMed Central Ltd.

This is an Open Access article distributed under the terms of the Creative Commons Attribution License (http://creativecommons.org/licenses/by/2.0), which permits unrestricted use, distribution, and reproduction in any medium, provided the original work is properly cited.

\begin{abstract}
Background: Children with Severe Combined Immunodeficiency (SCID) lack autologous T lymphocytes and present with multiple infections early in infancy. Omenn syndrome is characterized by the sole emergence of oligoclonal auto-reactive $T$ lymphocytes, resulting in erythroderma and enteropathy. Omenn syndrome (OS) shares the genetic aetiology of T-B-NK+ SCID, with mutations in RAGI, RAG2, or DCLREIC.

Methods: Patients diagnosed with T-B-NK+ SCID or phenotypes suggestive of Omenn syndrome were investigated by molecular genetic studies using gene tightly linked microsatellite markers followed by direct sequencing of the coding regions and splice sites of the respective candidate genes.

Results: We report the molecular genetic basis of T-B-NK+ SCID in 22 patients and of OS in seven patients all of Arab descent from Saudi Arabia. Among the SCID patients, six (from four families) displayed four homozygous missense mutations in RAGI including V433M, R624H, R394W, and R559S. Another four patients (from three familes) showed 3 novel homozygous RAG2 mutations including KI27X, SI8X, and Q4X; all of which predict unique premature truncations of RAG2 protein. Among Omenn patients, four (from two families) have S40 IP and R396H mutations in RAGI, and a fifth patient has a novel I444M mutation in RAG2. Seven other patients (six SCID and one OS) showed a gross deletion in exons I-3 in DCLREIC. Altogether, mutations in RAGI/2 and DCLREIC account for around $50 \%$ and $25 \%$, respectively, in our study cohort, a proportion much higher than in previous reported series. Seven (24\%) patients lack a known genetic aetiology, strongly suggesting that they carry mutations in novel genes associated with SCID and Omenn disorders that are yet to be discovered in the Saudi population.
\end{abstract}

Conclusion: Mutation-free patients who lack a known genetic aetiology are likely to carry mutations in the regulatory elements in the SCID-causing genes or in novel genes that are yet to be discovered. Our efforts are underway to investigate this possibility by applying the whole genome scans on these cases via the use of Affymetrix high density DNA SNP chips in addition to homozygosity mapping. 


\section{Background}

Severe Combined Immunodeficiency (SCID) is characterized by a block in T lymphocyte differentiation that is variably associated with abnormal development of other lymphocyte lineages, i.e. B or NK lymphocytes or more rarely of the myeloid lineage $[1,2]$. The overall SCID frequency is estimated to be 1 in 75,000-100,000 of live births $[3,4]$. The clinical presentation is fairly uniform and is characterized by early onset and diverse infections. Oral candidiasis, persistent diarrhea with growth impairment and/or interstitial pneumonitis are the most frequent infectious manifestations leading to diagnosis [5].

SCID is charecterized by high level of genetic and clinical heterogeniety, as more than 10 conditions have been identified and can be distinguished according to cellular phenotype, inheritance pattern, and the responsible genes [6-12]. Infants with autosomal recessive SCID caused by mutations in recombination activating genes $1 \& 2$ (RAG1 $\& R A G 2$ ) [13] that are necessary for the somatic rearrangement of antigen receptor genes on T- and B-lymphocytes $[14,15]$, or in DCLRE1C (Artemis) [16], resemble all other forms of SCID in their infection susceptibility, however their lymphocyte phenotype is charecterized by predominantly circulating NK cells and undetectable B or T lymphocytes (T-B-NK+ SCID) [13]. RAG1, RAG2, and $D C L R E 1 C$ are the primary genes responsible for the T-B$\mathrm{NK}^{+}$SCID phenotype [17] and in a recent report, mutations in LIG4 were also documented in patients with this phenotype who also have microcephaly and developmental delay [18].

In addition to causing the SCID phenotype, hypomorphic mutations in RAG1 or RAG2 can lead to partially impaired $\mathrm{V}(\mathrm{D}) \mathrm{J}$ recombinational activity resulting in Omenn syndrome (OS) $[19,20]$. OS can also result from defects in other genes including DCLRE1C [21], LIG4 [22], IL7RA [23], common gamma chain [24], ADA [25], RMRP [26] and CHD7 [27]. In OS, the absolute lymphocyte count is elevated due to circulating non-functional oligoclonal $\mathrm{T}$ lymphocytes $[28,29]$. There is also a third group of patients, called "atypical SCID/OS" or "leaky SCID" patients because the clinical features do not exactly match those of the previous two categories of patients [5].

A high number of patients bearing mutations in RAG genes has been reported so far (RAGbases are freely accessible on the web at http://www.uta.fi/imt/bioinfo/ RAG1base and http://www.uta.fi/imt/bioinfo/ RAG2base). Various mutations have been identified, both in RAG1 and RAG2, which can be either severe, leading to null alleles, or mild, leading to hypomorphic alleles that can still maintain a residual enzymatic activity. Null mutants typically predominate in classical T-B- SCID, as no productive rearrangement of the T cell receptor (TCR) or B-cell receptor (BCR) can occur, while missense mutations predominate in OS and leaky SCID [30].

The same mutation in different individuals usually lead to similar phenotype. There are also a few cases in which the same mutation gives rise to different clinical presentation $[5,19]$ suggesting that epistasis or other as yet unknown factors may play a role in determining the clinical picture and outcome.

Little is known about the molecular aspects of SCID or Omenn syndrome in Saudi patients. The incidene of SCID in Saudi population (representative of Arabian populations) is not well established but an initial data have suggested a 20 fold increase relative to the international figures [31]. This is mostly due to the high rate of consanguinity in the country (56\%) [32]. Similar finding can be also extrapolated from the Iranian registery for primary immune deficiencies [33]. The underlying molecular genetic defects responsible for SCID and OS in Saudi population have not been previously studied. In this report, we document for the first time the molecular findings on Saudi patients with T-B-NK+ SCID and Omenn syndrome.

\section{Methods \\ Patients}

On the basis of the clinical presentation and the immunologic data the patients were divided into 2 subgroups, T-B$\mathrm{NK}^{+}$SCID and Omenn syndrome. Total of 22 patients with T-B-NK+ SCID phenotype and seven Omenn syndrome patients who have been followed by the immunodeficincy clinics at King Faisal Specialist Hospital and Research Center (KFSHRC) were enrolled in this study. The clinical and immunological characterestics of all patients are shown in Additional Files 1 \&2. All patients were screened for mutations in RAG1, RAG2, and DCLRE1C genes. Patients who are negative for all three genes were then sequenced for LIG4. This study was approved by the Institution Review Board (IRB) at KFSHRC, and an informed consent was obtained for each of the participating patients.

\section{Cellular and immunological assays}

Peripheral leukocyte markers were determined with immunofluorescence staining and flow cytometry [34] using labeled antibodies for T cells (CD3, CD4 and CD8), natural killer cells (CD16 and CD56), and B cells (CD19) (Antibodies were acquired from Becton, Dickinson \& Co, San Jose, California, USA). T-cell function was determined in vitro by proliferative responsiveness to phytohemagglutinin stimulation as described [35]. Serum Ig levels were measured by nephelometry [36].

\section{Clinical samples and DNA isolation}

For prospective patients, peripheral blood samples were obtained from the patients and parents through veni- 
puncture. Genomic DNA was then extracted from the blood samples using standard techniques [37]. For patient who underwent stem cell transplantion before the study initiation, pretransplant stored DNA was obtained from the HLA typing laboratory at KFSH\&RC for molecular analysis.

\section{Genotyping by microsatellite markers}

Homozygosity mapping based on the utilization of microsatellite markers flanking RAG1/RAG2 (D11S4203, D11S4083, and D11S4102) or DCLRE1C (D10S1725, D10S191, and D10S1653) was used as a prerequisite for the whole candidate gene sequencing. Inversely, heterozygosity was used for exclusion of whole gene sequencing. The rationale for using homozygosity mapping was because the studied cases in this report were almost exclusively from consanguineous families (patient 19 in Additional File 1 was the only exception), and hence an autosomal recessive homozygous founder mutation is likely to be the cause of the observed phenotype in these cases. For LIG4, direct sequencing of the coding region of this gene was implemented without the microsatellite evaluation; this gene is constituted by 2 exons and only the second exon is coding. For genotyping, PCR amplification was performed on a thermocycler (DNA Engine Tetrad. MJ Research, USA) in a total volume of $25 \mu \mathrm{l}$, containing 10 ng DNA, $50 \mathrm{mM} \mathrm{KCl}, 10 \mathrm{mM}$ Tris- $\mathrm{HCl}(\mathrm{pH}$ 9.0), $1.5 \mathrm{mM} \mathrm{MgCl} 2,0.1 \%$ Triton $\mathrm{X}-100,0.25 \mathrm{mM}$ of each dNTP, $0.5 \mathrm{pM}$ of each primer (one fluorescently labeled), and 1 Unit of Taq polymerase (QIAGEN, D-40724, Hilden, Germany). Following the assembly of the reaction mix, PCR was carried out by an initial denaturation step at $95^{\circ} \mathrm{C}$ for $15 \mathrm{~min}$ followed by 30 cycles of denaturation at $95^{\circ} \mathrm{C}$ for $30 \mathrm{sec}$, annealing at $50^{\circ} \mathrm{C}$ for $30 \mathrm{sec}$ and extension at $72^{\circ} \mathrm{C}$ for $30 \mathrm{sec}$ followed by a final extension step at $72^{\circ} \mathrm{C}$ for $4 \mathrm{~min}$. Amplification products were separated using a MegaBace 1000 capillary sequencer and sized using the Genetic Profiler software package (Amersham, Sunnyvale, CA, USA).

\section{Sequencing of RAG I, RAG2, DCLREIC, and LIG4}

Coding sequences of RAG1, RAG2, DCLRE1C, and LIG4 were amplified from genomic DNA. DNA samples were obtained before stem cell transplantation of the participating patients. DNA was also obtained from the parents when possible. Prior to a full gene sequencing, genotyping of three markers flanking the above genes was usesd as a gene exclusion criterion when heterozygosity is established. Sequencing primers were designed for the amplification of the four genes based on the sequences reported in databases (RAG1, M29474; RAG2, M94633; DCLRE1C, NM_022487; LIG4, NM_0002312). Sequencing primers were designed and optimized for the entire coding region of each of the three genes. Primer sequences and PCR conditions are available from the authors upon request. PCR amplifications were performed in $25 \mu \mathrm{l}$ reactions as previously described [38]. PCR products were sequenced directly using the DYEnamic ET Dye Terminator Cycle Sequencing Kit (Amersham Biosciences; Piscataway, NJ, USA; http://www.amersham.com) on a MegaBACE 1000 DNA Analysis System (Molecular Dynamics; Sunnyvale, CA, USA). Sequence data were aligned against the reference GenBank sequences and examined for variation. For novel mutation verification, anonymized 96 DNA samples derived from normal Saudi blood donors were sequenced.

\section{Results}

\section{Patient clinical and immunological characteristics}

T-B-NK+ SCID phenotype

Twenty two patients belong to this category were identified and recruited. They presented with the typical clinical manifestations including chronic diarrhea, failure to thrive, severe opportunistic infections, lymphopenia, absent or reducded T- and B-lymphocytes, hypogammaglobulinemia, and poor lympohocytes response to mitogen stimulation (Additional File 1).

\section{Omenn phenotype}

Seven patients were identified with the typical clinical presentation of diffuse exfoliative erythroderma, chronic diarrhea, failure to thrive, severe opportunistic infections, generalized lymphadenopathy, and hepatosplenomegaly. They had detectable activated T-lymphocytes with low circulating B-lymphocytes and no evidence of maternal Tcell engrafment as indicated by the short tandem repeat (STR) analysis, hypogammaglobulinemia, and poor lympohocytes response to mitogen stimulation (Additional File 2). None of our patients had microcephaly or severe developmental delay.

The overwhelming majority of these patients 28/29 (97\%) belong to consanguineous parents all of which were of Saudi decent. None of our patients had a family history typical of X-linked inheritance although this could not be definitely ruled out in other Saudi families where the affected individuals are only males.

\section{Genotyping of OS and T-B-NK+ SCID patients}

RAG1/2 locus genotyping was performed by using a set of three microsatellite markers (D11S4203, D11S4083, and D11S4102) spaning a $1 \mathrm{cM}$ interval on chr 11 . A second set ot 3 microsatellite markers (D10S1725, D10S191, and D10S1653) spanning a $2 \mathrm{cM}$ locus on chr 10 which harbors DCLRE1C was also used. 22 patients with the T-B$\mathrm{NK}^{+}$SCID phenotype and seven patients with OS were genotyped by using both marker sets. A gene locus was considered homozygous if at least the second (central) marker in each marker set is homozygous; in such instances the respected gene's whole coding regions were 
subsequently analyzed for mutation by direct sequencing. From the overall 29 patients, homozygosity was demonstrated in 19 for the RAG1/2 locus, and in seven for the DCLRE1C locus. Homozygous RAG1 or RAG2 mutations were detected (as will be described in the next section) only in 15 leaving four without a detectable mutation (mutation-free). One or both parents of these four mutation-free patients were curiously homozygous for the RAG1/2 locus. All seven patients homozygous for the DCLRE1C locus subsequently showed a novel gross deletion in DCLRE1C.

\section{Gene sequencing for T-B-NK+ SCID and OS patients}

Twenty two patients (P1-P22) (Additional File 1) with T$\mathrm{B}^{-} \mathrm{NK}^{+}$were identified and screened for mutation in RAG1, RAG2, and DCLRE1C. Patients who did not show presence of mutation in any of these three genes were subsequently screened for mutation in LIG4 by direct gene sequencing. Ten patients were positively identified with homozygous mutations in RAG1/2 (Additional File 3). Among them, six (from four families) have four different missense mutations in RAG1. The remaining four positive patients (from three familes) have three novel homozygous RAG2 nonsense mutations.

Parents of all ten patients with RAG1 or RAG2 mutations were confirmned as carriers (heterozygous) of the respective mutation. Six patients showed a novel gross deletion mutation spanning exons 1-3 in DCLRE1C. No mutation was detected in the coding regions of RAG1, RAG2 or DCLRE1C genes for any of the remaining $6 \mathrm{~T}-\mathrm{B}-\mathrm{NK}+\mathrm{SCID}$ patients (P16-P21; 27\%).

Five families with Omenn syndrome (OS) that include seven affected patients (OS1-OS7) were also studied (Additional File 2). Variable homozygous mutations, including one novel, were identified in all families except one (F2) (Additional File 4); no mutation in RAG1, RAG2, or DCLRE1C was found in OS3 (F2) patient. OS7 (F5) patient showed the presence of the three-exon deletion in DCLRE1C that was also seen previously in the T-B-NK+ SCID patients. Parents of the patients with positive RAG1 and RAG2 mutations were confirmned as carriers of the respective mutation.

\section{Discussion}

In this communication, we are reporting the molecular characterization of a cohort of 29 Saudi patients, 22 of which are of the T-B-NK+ SCID phenotype and seven with Omenn syndrome. Although the underlying molecular causes of T-B-NK+ SCID and Omenn syndrome are well established world-wide, the aetiology of these disorders is yet to be defined in Saudi population.

Within the $22 \mathrm{~T}-\mathrm{B}-\mathrm{NK}^{+}$SCID patients, ten (46\%) were found to carry homozygous mutations in RAG1 or RAG2, and six $(27 \%)$ in DCLRE1C. The remaining six patients $(27 \%)$ had no detectable mutation in the coding regions of RAG1, RAG2, or DCLRE1C. None of those patients were tested for radiosensitivity to exclude the recently described causes of T-B-NK+ SCID such as Cernunnos [39] or DNAPK deficiency [40]; the lack of growth retardation and microcephaly, however, argues against Cernunnos deficiency but does not exclusively rule out the involvement of either of these 2 genes.

Out of 6 RAG1 mutations identified, four proviously reported (R396H, R394W, S401P and V433M), are interestingly localized within the nonamer binding domain (NBD) which is constituted of a 56 amino acid strech between residues 392-447 in the encoded 1040-aa RAG1 protein http://www.expasy.org/uniprot/P15918. R394W and $\mathrm{R} 396 \mathrm{H}$ are critically present within the highly-conserved N-terminus amino acids 392-396 of the NBD which is composed of 5 unique residues $\left({ }^{392} \mathrm{G}^{393} \mathrm{G}^{394} \underline{\mathrm{R}}^{395} \mathrm{P}^{396} \underline{\mathrm{R}}\right)$. The resulting non-conserved amino acid substitutions within this conserved domain will most likely result in profound loss of function of RAG1, and hence abrogation of the protein's interaction with the recombination signal sequence (RSS) during cellular DNA recombination. This notion is supported by the severly reduced number of circulating T- and B-lymphocytes in these patients combined with a severe reduction in Ig levels (Additional Files 1 \&2). Furthermore, previous reports also suggested mutations of the basic residues in this conserved domain had led to complete loss of RAG1 function as demonstrated by inability of the NBD-mutated RAG1 to mediate $\mathrm{V}(\mathrm{D}) \mathrm{J}$ recombination [41-43]. The fifth RAG1 mutation, R559S, on the other hand is localized to the catalytic domain of RAG1 which interact with RAG2. R559S is a destructive non-conservative change from large size and basic (R) to small size and polar (S) amino acid, a change that is likely to disturb the conformational structure of RAG1 as a consequence, and hence abrogation of its ability to mediate $\mathrm{V}(\mathrm{D}) \mathrm{J}$ recombination. This speculation is indeed supported by a previous report describing the same mutation (R559S) to be associated with a reduced ability to mediate V(D)J recombination [44]. Similar to R559S, R624H is also a nonconservative change from large size and basic (R) to medium size and polar $(\mathrm{H})$ amino acid. This change is also likely to disturb the structure of RAG1 because of the mutation's critical location in the RAG2-interacting core region. $\mathrm{R} 624 \mathrm{H}$ among other mutations located in the core region of RAG1 were shown to result in a dramatic reduction in the mutant RAG1 recombination frequencies compared to the wild-type RAG1 [19].

RAG2 mutations (Q4X, S18X, and K127X) found in the T$\mathrm{B}-\mathrm{NK}^{+} \mathrm{SCID}$ patients were very intreguing since all of them were of the early truncation type. Even if the mutatnt transcripts escape the nonsense-mediated mRNA decay 
(NMD), the protein they encode would be missing the key RAG2 domains, including the active core within which lies the nuclear localization signal (NLS). Therefore, the associated phenotype in the patients with these truncation mutations is most probably a reflection of a failed RAG1-RAG2 interaction which occurs normally in the nucleus, and is required during T-cell receptor (TCR) and B-cell immunoglobulin (Ig) rearrangements [5,28]. The fourth RAG2 missense mutation, I444M, was detected in one patient (OS6). As shown in Additional File 2, this patient has only a marginal total lymphocyte count (620/ $\mathrm{mm} 3$ ), and thus the patient may have a residual RAG2 activity. This is an appealing proposal because both I\&M amino acids are of similar physico-chemical properties, and both are medium size and hydrophobic. This mutation is probably of the hypomorphic type which is consistant with the mild phenotype seen in this patient.

Previous reports have revealed that truncated core proteins, encompassing amino acids 384-1008 for RAG1 and amino acids 1-387 for RAG2, are necessary and sufficient to rearrange artificial $\mathrm{V}(\mathrm{D}) \mathrm{J}$ recombination substrates in vitro $[45,46]$. Our study has identified 8 homozygous missense and 3 truncation mutations (Additional Files 3 \&4) that all map to the RAG1 and RAG2 core regions. In case of the DCLRE1C three-exon deletion (exons 1-3) that we identified in seven affected patients (six T-B-NK+ SCID and one OS), it is anticipated that such mutaion will lead to a non-functional truncated protein product (provided the intact exons 4-14 are transcribed and translated). Unfortuanately, further molecular investigation is not possible because this is a retrospective study and these patients had already received bone marrow transplantation. Interestingly however is that this mutation is capable of producing either SCID or OS phenotypes, as seen in our patients.

In correlating genotype to phenotype, it is clear that all RAG1 and RAG2 mutations reported here, with the exception of I444M in OS2, are also associated with severe SCID or OS. Additionally, it is also noteworthy that all our patients who are negative for mutations in RAG1, RAG2, or DCLRE1C were also negative for LIG4 indicating that mutations in the latter are not a common cause of SCID or OS in Saudi patients. This is consistant with data reported previously in other populations [5]. Genotyping and sequencing results for cases in which multiple tribespecific RAG1/2 mutations were detected excluded the common founder hypothesis for this subset of patients; however the DCLRE1C 3-exon deletion detected in several other patients form different families may either be a recurrent or a founder one and remains open for further exploration.

\section{Conclusion}

This study shows that mutations in RAG1/2 and DCLRE1C are seen in different Saudi patients with SCID or OS phenotype. Given the observed level of consanguinity which approaches $100 \%$ we believe that genomewide homozygosity mapping is likely to reveal novel loci associated with these phenotypes in the mutation-free patients for whom linkage to the above 3 loci has been excluded and this is being actively pursued by our group.

\section{Competing interests}

The authors declare that they have no competing interests.

\section{Authors' contributions}

OA wrote the manuscript, designed the study, and conducted the genetic analysis and interpretation. AG, SM, RA, HD and BS carried out the patient clinical evaluation. FA and HS carried out the genetic and sequence analyis. HM co-designed the study, wrote the clinical summary of the patients, and supervised the clinical evaluation and patient chart review. All authors read and contributed to the manuscript writing.

\section{Additional material}

\section{Additional file 1}

Table S1 - Laboratory and clinical characteristics of patients with $T^{-}$ $\mathrm{B}^{-} \mathrm{NK}^{+}$severe combined immunodeficiency. Laboratory and clinical characteristics.

Click here for file

[http://www.biomedcentral.com/content/supplementary/14712350-10-116-S1.doc]

\section{Additional file 2}

Table S2 - Laboratory and clinical characteristics of patients with Omenn Syndrome. Laboratory and clinical characteristics.

Click here for file

[http://www.biomedcentral.com/content/supplementary/14712350-10-116-S2.doc]

\section{Additional file 3}

Table S3 - Mutations detected in patients with $\mathrm{T}^{-} \mathrm{B}^{-} \mathrm{NK}^{+}$Severe combined immunodeficiency. Mutations listing.

Click here for file

[http://www.biomedcentral.com/content/supplementary/14712350-10-116-S3.doc]

\section{Additional file 4}

Table S4 - Mutations detected in patients with Omenn syndrome. Mutations listing.

Click here for file

[http://www.biomedcentral.com/content/supplementary/14712350-10-116-S4.doc] 


\section{Acknowledgements}

This study was wholly funded by King Faisal Specialist Hospital and Research Center, and no other funding resources have contributed to carrying out the research presented in this manuscript. The authors would like to thank Dr. Brian Meyer, Chairman of Genetics Department, for his positive support and guidance throughout this project, Dr. Fowzan Al-Kuraya, Genetics Department, for his editorial suggestions and the Research Center Administration for their unlimited support.

\section{References}

I. Fischer A, Cavazzana-Calvo M, De Saint Basile G, DeVillartay JP, Di Santo JP, Hivroz C, Rieux-Laucat F, Le Deist F: Naturally occurring primary deficiencies of the immune system. Annu Rev Immunol 1997, I 5:93-I24.

2. WHO, Sg Report: Primary Immunodeficiency Diseases Report of an IUIS Scientific Committee. Clinical \& Experimental Immunology 1999, I I 8(s I): I-28.

3. Buckley RH, Schiff RI, Schiff SE, Markert ML, Williams LW, Harville TO, Roberts JL, Puck JM: Human severe combined immunodeficiency: genetic, phenotypic, and functional diversity in one hundred eight infants. J Pediatr 1997, 130:378-87.

4. Stephan JL, Vlekova V, Le Deist F, De Saint Basile G, Donadieu J, Durandy A, Blanche S, Griscelli C, Fischer A: A retrospective single-center study of clinical presentation and outcome in 1 I 7 patients with severe combined immunodeficiency. Immunodeficiency 1993, 4:87-8.

5. Villa A, Sobacchi C, Notarangelo LD, Bozzi F, Abinun M, Abrahamsen TG, Arkwright PD, Baniyash M, Brooks EG, Conley ME, et al:: V(D)J recombination defects in lymphocytes due to RAG mutations: severe immunodeficiency with a spectrum of clinical presentations. Blood 2001, 97:81-8.

6. de Saint Basile G, Geissmann F, Flori E, Uring-Lambert B, Soudais C, Cavazzana-Calvo M, Durandy A, Jabado N, Fischer A, Le Deist F: Severe combined immunodeficiency caused by deficiency in either the delta or the epsilon subunit of CD3. J Clin Invest 2004, I | 4: I5 I 2-7.

7. Giblett ER, Anderson JE, Cohen F, Pollara B, Meuwissen HJ: Adenosine-deaminase deficiency in two patients with severely impaired cellular immunity. Lancet 1972, 2: I067-9.

8. Kung C, Pingel JT, Heikinheimo M, Klemola T, Varkila K, Yoo LI, Vuopala K, Poyhonen M, Uhari M, Rogers M, et al.: Mutations in the tyrosine phosphatase CD45 gene in a child with severe combined immunodeficiency disease. Nat Med 2000, 6:343-5.

9. Macchi P, Villa A, Giliani S, Sacco MG, Frattini A, Porta F, Ugazio AG, Johnston JA, Candotti F, O'Shea JJ, et al.: Mutations of Jak-3 gene in patients with autosomal severe combined immune deficiency (SCID). Nature 1995, 377:65-8.

10. Noguchi M, Yi H, Rosenblatt HM, Filipovich AH, Adelstein S, Modi WS, McBride OW, Leonard W]: Interleukin-2 receptor gamma chain mutation results in $X$-linked severe combined immunodeficiency in humans. Cell 1993, 73:147-57.

II. Puel A, Ziegler SF, Buckley RH, Leonard WJ: Defective IL7R expression in $\mathrm{T}(-) \mathrm{B}(+) \mathrm{NK}(+)$ severe combined immunodeficiency. Nat Genet 1998, 20:394-7.

12. Tchilian EZ, Wallace DL, Wells RS, Flower DR, Morgan G, Beverley PC: A deletion in the gene encoding the CD45 antigen in a patient with SCID. J Immunol 200I, I 66:1308-13.

13. Schwarz K, Gauss GH, Ludwig L, Pannicke U, Li Z, Lindner D, Friedrich W, Seger RA, Hansen-Hagge TE, Desiderio S, et al:: RAG mutations in human B cell-negative SCID. Science 1996, 274:97-9.

14. Mombaerts P, lacomini J, Johnson RS, Herrup K, Tonegawa S, Papaioannou VE: RAG-I-deficient mice have no mature B and T lymphocytes. Cell 1992, 68:869-77.

15. Shinkai Y, Rathbun G, Lam KP, Oltz EM, Stewart V, Mendelsohn M, Charron J, Datta M, Young F, Stall AM, et al.: RAG-2-deficient mice lack mature lymphocytes owing to inability to initiate V(D)J rearrangement. Cell 1992, 68:855-67.

16. Moshous D, Callebaut I, de Chasseval R, Corneo B, Cavazzana-Calvo M, Le Deist F, Tezcan I, Sanal O, Bertrand Y, Philippe N, et al.: Artemis, a novel DNA double-strand break repair/V(D)J recombination protein, is mutated in human severe combined immune deficiency. Cell 200I, I 05:177-86.
17. Buckley $\mathrm{RH}$ : Molecular defects in human severe combined immunodeficiency and approaches to immune reconstitution. Annu Rev Immunol 2004, 22:625-55.

18. Burg M van der, van Veelen LR, Verkaik NS, Wiegant WW, Hartwig NG, Barendregt BH, Brugmans L, Raams A, Jaspers NG, Zdzienicka $M Z$, et al.: A new type of radiosensitive T-B-NK+ severe combined immunodeficiency caused by a LIG4 mutation. J Clin Invest 2006, I | 6: 137-45.

19. Corneo B, Moshous D, Gungor T, Wulffraat N, Philippet P, Le Deist FL, Fischer A, de Villartay JP: Identical mutations in RAG I or RAG2 genes leading to defective $V(D) J$ recombinase activity can cause either T-B-severe combined immune deficiency or Omenn syndrome. Blood 200I, 97:2772-6.

20. Villa A, Santagata S, Bozzi F, Giliani S, Frattini A, Imberti L, Gatta LB, Ochs HD, Schwarz K, Notarangelo LD, et al.: Partial V(D)J recombination activity leads to Omenn syndrome. Cell 1998, 93:885-96.

21. Ege M, Ma Y, Manfras B, Kalwak K, Lu H, Lieber MR, Schwarz K, Pannicke U: Omenn syndrome due to ARTEMIS mutations. Blood 2005, I05:4179-86.

22. Grunebaum E, Bates A, Roifman CM: Omenn syndrome is associated with mutations in DNA ligase IV. J Allergy Clin Immunol 2008, 1 22: $1219-20$

23. Giliani S, Bonfim C, de Saint Basile G, Lanzi G, Brousse N, Koliski A, Malvezzi M, Fischer A, Notarangelo L, Le Deist F: Omenn syndrome in an infant with IL7RA gene mutation. J Pediatr 2006, I 48(2):272-4

24. Wada T, Yasui M, Toma T, Nakayama Y, Nishida M, Shimizu M, Okajima M, Kasahara $Y$, Koizumi S, Inoue M, et al:: Detection of T lymphocytes with a second-site mutation in skin lesions of. Blood 2008, I | 2(5): | 872-5.

25. Roifman C, Zhang J, Atkinson A, Grunebaum E, Mandel K: Adenosine deaminase deficiency can present with features of Omenn syndrome. J Allergy Clin Immunol 2008, I 2 I (4): I056-8.

26. Roifman C, Gu Y, Cohen A: Mutations in the RNA component of RNase mitochondrial RNA processing might cause. Allergy Clin Immunol 2006:897-903.

27. Gennery A, Slatter M, Rice J, Hoefsloot L, Barge D, McLean-Tooke A, Montgomery T, Goodship J, Burt A, Flood T, et al.: Mutations in CHD7 in patients with CHARGE syndrome cause T-B + natural killer. Clin Exp Immunol 2008, I 53(I):75-80.

28. Brooks EG, Filipovich AH, Padgett JW, Mamlock R, Goldblum RM: Tcell receptor analysis in Omenn's syndrome: evidence for defects in gene rearrangement and assembly. Blood 1999 , 93:242-50.

29. Rieux-Laucat F, Bahadoran P, Brousse N, Selz F, Fischer A, Le Deist $F$, De Villartay JP: Highly restricted human $T$ cell repertoire in peripheral blood and tissue-infiltrating lymphocytes in Omenn's syndrome. J Clin Invest 1998, 102:312-21.

30. Villa A, Notarangelo LD, Roifman CM: Omenn syndrome: Inflammation in leaky severe combined immunodeficiency. J Allergy Clin Immunol 2008.

3I. Suliaman F, Al-Ghonaium A, Harfi H: High Incidence of Severe Combined Immune Deficiency in the Eastern Province of Saudi Arabia. Pediatric Asthma, Allergy \& Immunology 2006, 19:14-18.

32. El Mouzan MI, AI Salloum AA, Al Herbish AS, Qurachi MM, AI Omar $A A$ : Consanguinity and major genetic disorders in Saudi children: a community-based cross-sectional study. Ann Saudi Med 2008, 28:169-73

33. Yeganeh M, Heidarzade $M$, Pourpak Z, Parvaneh $N$, Rezaei $N$, Gharagozlou M, Movahedi M, Shabestari MS, Mamishi S, Aghamohammadi A, et al.: Severe combined immunodeficiency: a cohort of 40 patients. Pediatr Allergy Immunol 2008, 19:303-6.

34. Macnamara B, Palucka KA, Porwit-MacDonald A: Balance between proliferation and apoptosis in leukemic cell lines resistant to cytostatics. Leuk Lymphoma 1999, 36:179-89.

35. Roep BO, Kallan AA, Duinkerken G, Arden SD, Hutton JC, Bruining $\mathrm{G}$, de Vries RR: T-cell reactivity to beta-cell membrane antigens associated with beta-cell destruction in IDDM. Diabetes 1995, 44:278-83.

36. Routier FH, Hounsell EF, Rudd PM, Takahashi N, Bond A, Hay FC, Alavi A, Axford JS, Jefferis R: Quantitation of the oligosaccharides of human serum IgG from patients with rheumatoid arthritis: a critical evaluation of different methods. J Immunol Methods 1998, 2 I 3: I |3-30. 
37. Miller SA, Dykes DD, Polesky HF: A simple salting out procedure for extracting DNA from human nucleated cells. Nucleic Acids Res 1988, 16:1215.

38. Kambouris M, Banjar H, Moggari I, Nazer H, Al-Hamed M, Meyer BF: Identification of novel mutations in Arabs with cystic fibrosis and their impact on the cystic fibrosis transmembrane regulator mutation detection rate in Arab populations. Eur J Pediatr 2000, 159:303-9.

39. Buck D, Malivert L, de Chasseval R, Barraud A, Fondaneche M, Sanal O, Plebani A, Stephan J, Hufnagel M, Le Deist F, et al.: Cernunnos, a novel nonhomologous end-joining factor, is mutated in human. Cell 2006, I 24(2):287-99.

40. Burg $M$ van der, ljspeert $H$, Verkaik $N$, Turul T, Wiegant $W$, Morotomi-Yano K, Mari P, Tezcan I, Chen D, Zdzienicka M, et al.: A DNAPKcs mutation in a radiosensitive T-B-SCID patient inhibits Artemis. J Clin Invest 2009, I I 9( I):91. 8.

4I. Difilippantonio MJ, McMahan CJ, Eastman QM, Spanopoulou E, Schatz DG: RAG I mediates signal sequence recognition and recruitment of RAG2 in V(D)J recombination. Cell I996, 87:253-62.

42. Huye LE, Purugganan MM, Jiang MM, Roth DB: Mutational analysis of all conserved basic amino acids in RAG-I reveals catalytic, step arrest, and joining-deficient mutants in the V(D)J recombinase. Mol Cell Biol 2002, 22:3460-73.

43. Spanopoulou E, Zaitseva F, Wang FH, Santagata S, Baltimore D, Panayotou G: The homeodomain region of Rag-I reveals the parallel mechanisms of bacterial and V(D)J recombination. Cell 1996, 87:263-76.

44. Kumaki S, Villa A, Asada H, Kawai S, Ohashi Y, Takahashi M, Hakozaki I, Nitanai E, Minegishi M, Tsuchiya S: Identification of anti-herpes simplex virus antibody-producing $B$ cells in a patient with an atypical RAG I immunodeficiency. Blood 200।, 98: |464-8.

45. Bogue $M$, Roth DB: Mechanism of $V(D)$ J recombination. Curr Opin Immunol 1996, 8:175-80.

46. Lewis SM: The mechanism of $V(D) J$ joining: lessons from molecular, immunological, and comparative analyses. Adv Immunol 1994, 56:27-150.

\section{Pre-publication history}

The pre-publication history for this paper can be accessed here:

http://www.biomedcentral.com/1471-2350/10/116/pre pub
Publish with Biomed Central and every scientist can read your work free of charge

"BioMed Central will be the most significant development for disseminating the results of biomedical research in our lifetime. "

Sir Paul Nurse, Cancer Research UK

Your research papers will be:

- available free of charge to the entire biomedical community

- peer reviewed and published immediately upon acceptance

- cited in PubMed and archived on PubMed Central

- yours - you keep the copyright
BioMedcentral 